\title{
IMPROVE SCIENTIFIC ABILITIES STUDENTS THROUGH MODEL DEVELOPMENT TESTING EXPERIMENTS
}

\author{
Abdul Basid*1, Rusli ${ }^{2}$ \\ ${ }^{1,2}$ Department of Physics, Universitas Islam Negeri Maulana Malik Ibrahim Malang \\ Gajayana Street No. 50 Malang 65144
}

\begin{abstract}
ABSTRAK
A Study on the development of a Testing Experiments model has been carried out which aims to improve the scientific abilities of students in the Physics Department. This study is motivated by the implementation of practicum that has almost no innovation, no change, always verifying patterned and less developing students' science process skills. The 4-D model R\&D approach was used to develop this practicum model. The instrument used is a handout that is equipped with a rubric as a practical guide and assessment guide. A total of 20 students were involved as research subjects. The results showed, in general, there was an increase in student scientific abilities. Of all the sub-abilities developed, the average percentage of achievement scores reached $60 \%$ in almost all sub-abilities after the 4 th or 5 th practicum or at the fourth or fifth week. However, there are sub-skills already reaching $60 \%$ in the 3rd practicum. Student and peer responses show that this practical model is better and more comprehensive in developing students' scientific abilities.
\end{abstract}

Keywords: Scientific Abilities; Model Development; Testing Experiments

\section{Introduction}

The results of a survey conducted by OECD (Organization for Economic Cooperation and Development) countries through an international study Program for International Student Assessment (PISA) in 2015 showed that Indonesia could only rank 69 out of 27 countries. These results indicate that the achievements of Indonesian students in Mathematics and Natural Sciences have not been good, even in the last three surveys, Indonesia ranks almost no change. The low PISA results indicate that our Mathematics and Natural Sciences education program is not in accordance with 21 st-century life needs, and even it is said that 70 per cent of Indonesian children have difficulty living in the 21 st century. The low PISA results also indicate the weakness of children Indonesian children in three main skills, better known as 21 st Century skills, in other words, our education has not succeeded in learning the three 21st Century skills. The three skills include: Resolving non-routine problems;
Apply knowledge in daily life, and; Communicate complex. ${ }^{1,2}$ Therefore, the three skills must be built by students with a systematic strategy by the teacher and planned carefully.

Similar results were also delivered by the 2015 Threads International Mathematics Science Study (TIMSS) which showed Indonesian students ranked 36th out of 49 countries. This result is almost the same as the results in 2011 which showed that the mastery of Mathematics and Natural Sciences of Indonesian students ranked 38 out of 45 countries and even under Palestine whose country was always in war. The last 10 years the results of PISA and TIMSS have always been hand in hand and run in place. ${ }^{3}$ The 2011 TIMSS evaluation results for grade VIII mathematics, Indonesia in the top 5 from the bottom (along with Syria, Morocco, Oman, Ghana). Indonesia's ranking (36/40 with a score of 386) has decreased from TIMSS 2007 (ranking 35/49 with a value of 397). The highest score was achieved by Korea (613), followed by Singapore (611). 
For science/science class VIII, Indonesia also occupies the top 5 from the bottom (along with Macedonia, Lebanon, Morocco, Ghana). Indonesia's ranking (39/42 with a score of 406) is below Palestine, Malaysia, Thailand, and Singapore ranked first with a value of $590 .{ }^{4}$

From the PISA and TIMSS reports above which show that the MIPA education program in secondary schools in Indonesia is still not in accordance with 21 st-century life needs, it is in harmony with the results of research in the field of science education in Higher Education in preparing students to meet the demands of the world of work in the century 21 The results of several studies unanimously concluded that preparing students to meet the demands of the world of work in the 21 st century is one of the main. ${ }^{5}$ The several recent studies about knowledge and abilities required in the workplace showed there are serious discrepancies between conventional physics learning, even learning methods which engage students' active involvement, and the need in the workplace. Furthermore, the summary report of business, industry, government agencies, and related groups recommended reforming science and technology education to take into-prepared students in the working world in the $21^{\text {st }}$ century. The report suggested three questions which must be answered through in-depth research, some of which are "What model of the skills are required?" and "How does the assessment work to make the students succeed in the workplace in the $21^{\text {st }}$ century. ${ }^{6}$

Dugan and Gott also studied the use of science by the workers in five science-based industries and a chemical plant. They found out that most of the scientific conceptual understandings used by workers are learned and obtained at the workplace, not at high schools or universities. They also summed up that the guarantee of knowledge to the procedural understanding of the scientific abilities seems critical. $^{7}$ Every science learning must be designed to help students gain valuable skills that will be applied in the workplace. In the laboratory, students must gain scientific skills such as designing experiments to solve problems, skills in gathering and analyzing data, evaluating assumptions and uncertainties, and communication skills. Often in learning in the laboratory students conduct experiments based on recipes such as practical instructions and verify the model. They rarely design their own experiments. ${ }^{8}$

By looking at the results of the PISA and TIMSS reports as well as some research on the use of science in the world of work, every study of science, especially physics learning must be designed how its graduates are able to face the 21st-century work world. choosing a physics major as a choice to face the 21 st-century church world, is the purpose of the lecture they attend only to help gain a conceptual and quantitative understanding of the basic principles of physics and the ability to use them in problem-solving?

Science learning requires not only knowledge content, but also scientific abilities that must be developed in order to succeed in the future. These scientific abilities (scientific abilities) include formulating questions, designing and conducting experiments, collecting, representing and analyzing data, modelling, testing hypotheses and solving complex problems. ${ }^{9}$

Besides these skills, the National Science Foundation (1996) and Bransford et al (1994) add that to face the world of work in the $21 \mathrm{st}$ century, physics learning must develop scientific literacy and critical thinking skills, communicate in detail external procedures, and can transfer these skills to other content beyond physics. ${ }^{10}$ Literacy is important, but education science and technology are essential to achieving the desired workforce competence, including critical thinking, complex communication skills, and problemsolving skills. Learning activities are designed to give them practice in the process of scientific investigation and technological design. ${ }^{6}$

Preliminary research on learning in the laboratory of the Physics Department of UIN Maulana Malik Ibrahim Malang. The 
statement is also in line with the statement of Etkina et al. above, where the conclusion is that the practicum manual used in general does not give students the opportunity to design their own experiments. Lab guidelines are directly adopted from equipment provider companies and student lab reports tend to be uniform. Indeed, this model allows students to be quite competent in measuring, collecting and analyzing experimental data but is less capable in assessing and evaluating experiments and divergent thinking. They only conduct observational experiments, never carry out testing experiments, even applied experiments. ${ }^{11}$

Based on the background as stated above, the general objective of this study is the development of a test experimental model in learning in the lab that can improve student scientific abilities. The specific objectives of this study are as follows: The compilation of testing experimental models (Testing Experiments) in learning in the laboratory. Compiled assessment guidelines from testing experimental models (Testing Experiments) for learning in the laboratory. It is known when there is an increase in students 'scientific skills in learning in the laboratory by the application of the testing experimental model. Knowing the patterns of enhancing the students' scientific abilities in learning in the laboratory by applying the test experimental model. This research is important to do, among others, because in this experimental testing model, students will have experience researching, arranging questions and designing methods to answer them, analyzing data, and discussing based on the results of interpretation. Students not only gain a conceptual and quantitative understanding of the principles of science, but are proficient in explaining data, building models, designing experiments to test hypotheses, and working with others.

\section{Methods}

To recognize the enhancement of students' scientific abilities, design lab learning model should be developed. The coursework chosen to design the model is
Physics Experiment enrolled by students of the Physics Department, Faculty of Science and Technology, UIN Maulana Malik Ibrahim Malang. A preliminary study was conducted to determine the objective of the study. The next step was designing students' handout and the assessment. In the research, the researcher solely developed the handout, while the assessment and scoring guideline used has been already developed by the Investigative Science Learning Environment (ISLE) Physics Network. The draft which has been validated by experts was tested on a limited basis. Dissemination model by doing actual implementation and analysis for improvement is a significant step in learning. In the design lab learning model, students do two or three experiments. There are three categories in this learning model, observational experiments, testing experiments, and application experiments. ${ }^{9,12}$

This paper will only show the result of the experiment in designing and conducting testing experiment done by students. In this category, students are to examine a new phenomenon which has not been discussed in the classroom. When students design an experiment, they need to think about how to collect the data suggested by laboratory handout and how to analyze them to find the patterns. There are nine topics of experiments designed in this model, yet only seven experiments are categorized into the observational experiment.

Scientific ability to design and conduct the testing experiment consists of several subabilities, such as ability to identify the hypothesis to be tested; ability to design a reliable experiment that tests the hypothesis; ability to distinguish between a hypothesis and a prediction; ability to make a reasonable prediction based on a hypothesis; ability to identify the assumptions made in making the prediction; ability to decide whether the prediction and the outcome agree/disagree; ability to make a reasonable judgment about the hypothesis. ${ }^{13}$

The above sub-abilities were linked to the scoring guidelines describing the achievements of the sub-abilities. The 
scoring scale was $0-3$, in which $0=$ not visible, $1=$ inadequate; $2=$ need improvement; 3 = adequate. The percentage of the answers given by students indicated the number of scientific abilities and the improvement as well as the period of improvement occurrence.

The design lab learning model involved 20 students of Physics Experiment Class. They were divided into seven groups, each of which consists of 2-3 students. This learning was assisted by one Top Assistant (TA) as a senior assistant and seven Laboratory Assistants (LA). The task of TA was to guide the implementation of learning as well as provide guidance to the LA. In addition, the TA provided feedback and answers to students with regard to practical implementation. TA was also to monitor and provide direct guidance on practical implementation and, at the same time, provide assessment carried out by the LA under the guidance of TA.

\section{Results and Discussion}

In implementing the Testing Experiments learning model in the trials, there are obstacles faced by students, both in the implementation of practical work and those related to the laboratory written report desired by this model. In this study, students are asked to make a report in accordance with the rubric in the handout (Work Guidelines) and no longer make a full report. This report is like an interim report but is more comprehensive, including reporting the steps taken to provide an assessment, and even giving advice from the practicum undertaken. These obstacles can be overcome with guidance from the Navy that oversees each topic and when discussing the results of the practicum by providing feedback before the next practicum activity is carried out

The development of students' scientific skills in designing and testing experiments from 1st to 6th experiments for all skills developed in this testing experiment is shown in Figure 1. In each experiment, students get the opportunity to develop their own scientific skills, which in each of these testing experiments there are seven scientific skills. To know the development of these skills a rubric or scoring or scoring guideline is used as stated in the previous section. Blue bar represents the average percentage of students' scientific ability performance scores. The longer blue bar indicates the higher percentage of student achievement on scientific abilities.

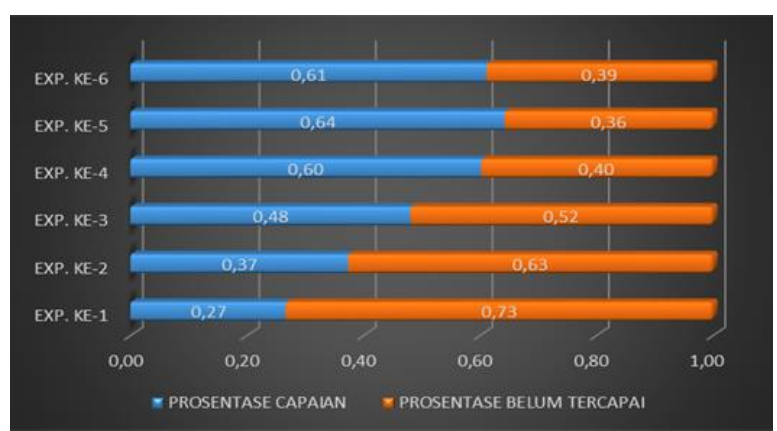

Figure 1. Graph of the average score percentage of scientific ability to design and conduct testing experiments

From the graph above it can be seen that the students' ability in designing and conducting testing experiments has reached above $60 \%$ after the 4 th experiment. This achievement tended to be stable in subsequent testing experiments with an average of $62 \%$. In the following pictures, the achievements will be described for each sub-skill achieved by students from the 1 st to 6th testing experiments. These results are obtained based on the written laboratory report for each experiment with a number of pages.

The development of students' abilities to identify the hypothesis to be tested is demonstrated in figure 2 . In the third experiment, the average score percentage for this ability is quite low, only reaching $40 \%$. The Students' ability in setting this hypothesis can be said to be the main subskills of scientific proficiency in designing and testing experiments. With the determination of the hypothesis for each topic of the experiment, it will be easy to carry out the next steps in each experiment and it will also be easy to compile laboratory work procedures or design an experiment to test it. The average percentage of this 
proficiency score reaches $65 \%$ after students pass the 4th experiment and tend to be stable in subsequent experiments with an average of $65 \%$. As with the overall ability to conduct test trials, there was a decrease in the average score on the last experiment.

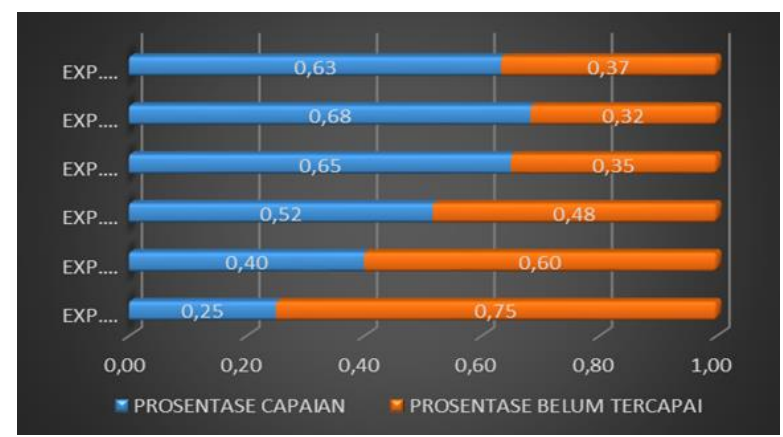

Figure 2. Graph of the average score percentage of scientific ability to identify the hypothesis to be tested

The ability to design experiments to test hypotheses is closely related and is determined by students' abilities in determining the hypotheses to be tested. Therefore students will not be able to design experiments to test hypotheses before the hypotheses are established. In designing experiments students must also understand what data will be obtained so that the hypotheses that they have previously set can be easier to test based on these data. From the student lab reports and it appears that their ability to design experiments in the initial experiments (1st to 3rd) on average is slightly better than their ability to determine the hypothesis. If we look at the graphs figures 2 and 3 looks for the acquisition of scores with almost the same increment pattern starting from the 1 st to the 6th experiments. From this pattern of ascension, it can be said that the students' ability in setting the hypothesis to be tested is very influential in their ability to design their experiments. From graphs 2 and 3, in the initial experiments (1st to $3 \mathrm{rd}$ ) it appears that if students are less capable in compiling hypotheses it results in their inability to design their experiments.

Student's ability to distinguish between hypotheses and predictions is no better than the two previous abilities. The average percentage score for this skill is lower than the previous ability. In the initial experiments the development of abilities was almost the same as the two previous ability for this experimental model, but after the 4th experiment only reached $60 \%$ and stable in this range (figure 4). This is possible because the abilities in making predictions have almost never been developed in every practicum in the previous five semesters. Understanding of predictions becomes better after TA provides an explanation of the results of the evaluation of their written reports.

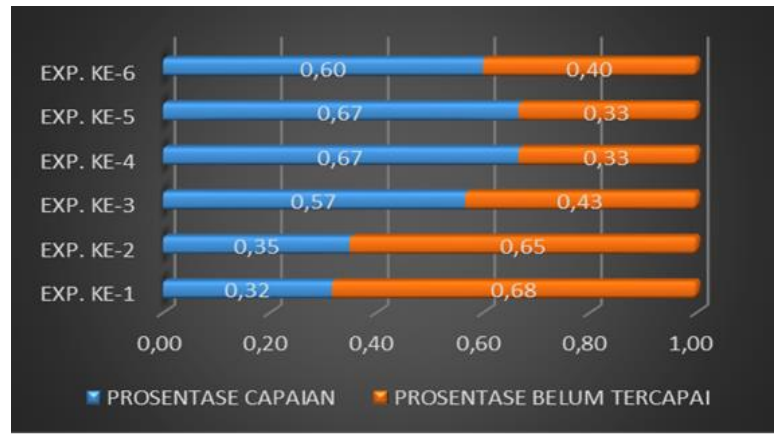

Figure 3. Graph of the average score percentage of scientific ability to design a reliable experiment that tests the hypothesis

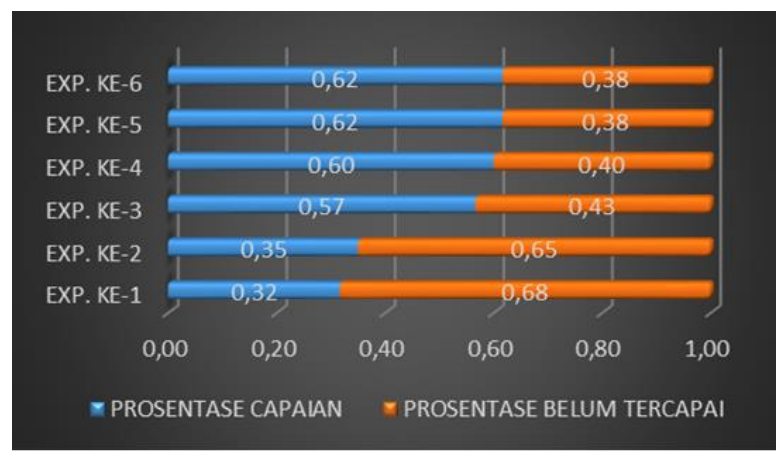

Figure 4. Graph of the average score percentage of scientific ability to distinguish between a hypothesis and a prediction

Students' ability to make reasonable predictions based on hypotheses is very dependent on their ability to set hypotheses on previous skills. These skills also depend on how students know the difference between hypotheses and predictions on previously developed skills. At the end of the experiment, the average percentage score was around 60\% less (Figure 5). There is a slight difference; namely this skill reaches 
$60 \%$ faster, that is after the 4th trial. By observing the written laboratory report it appears that their understanding of the prediction is still lacking so that until the 3rd experiment the average percentage score for this skill is still below $33 \%$.

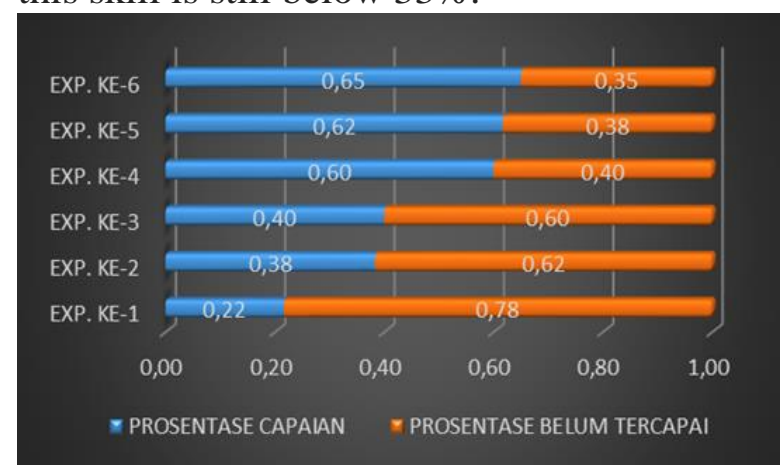

Figure 5. Graph of the average score percentage of scientific ability to to make a reasonable prediction based on a hypothesis

The relatively low average percentage of students making predictions was also related to their ability to identify assumptions related to predictions. The development of this skill in the last experiments was almost the same percentage as the previous skill, around $60 \%$ (figure. 6). From the written report the lab shows that the assumptions made in the initial experiments do not relate to what is desired from the results of their experiments. The assumptions they put forward are only related to the predictions or hypotheses they set after the 4th experiment and after the feedback from the lab reports they compiled. The assumptions they put forward also hardly improved, so their scores were relatively stable in the last three experiments.

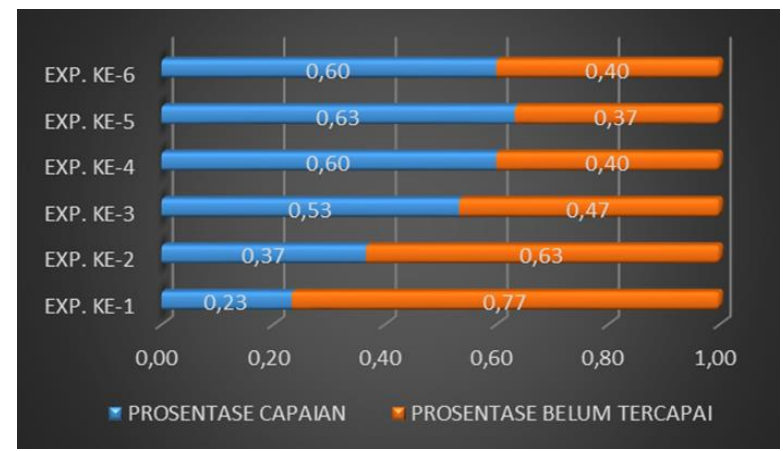

Figure 6. Graph of the average score percentage of scientific ability to ability to identify the assumptions made in making the prediction
Figure 7. shows the students' ability to make predictions has an impact on their ability to decide whether predictions agree or not with results. In other words, whether the predictions they made the match or not match the results of the experiment. Students' ability in making predictions shows that there is a match with their ability to decide whether or not the predictions match the results of the experiment. The average percentage of scores achieved by students for these two skills reached $60 \%$ after the 5th trial. This sub-skill is somewhat different from other skills, where in the last experiment the average score was below $60 \%$. From the results of the experiment report shows that students who can make predictions, they can provide an explanation of the results of the experiments they do related to the predictions they make. Their report also shows that when they did not make a prediction, they also could not make an explanation of the results of the experiment relating to the prediction. In general students' skills for this sub-skill are relatively lower than previous sub-skills for this type of experiment.

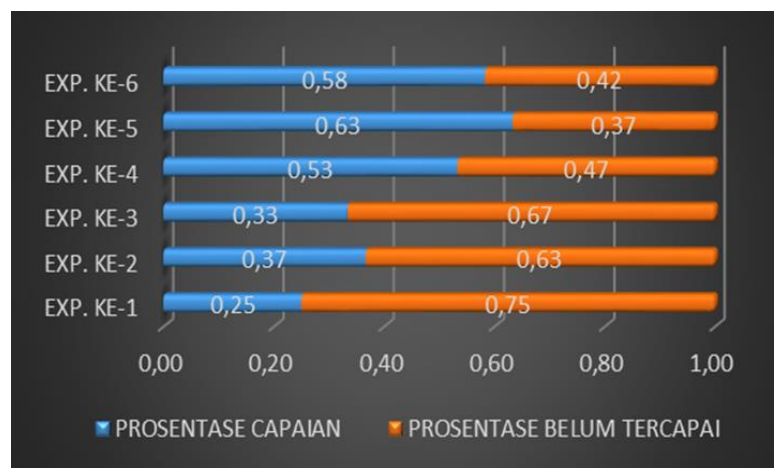

Figure 7. Graph of the average score percentage of scientific ability to decide whether the prediction and the outcome agree/disagree.

The percentage of students' ability to make plausible statements about hypotheses is generally lower than their ability to form hypotheses. The average percentage score in the last three trials reached $66 \%$. The average percentage of student scores for this sub-skill reached $60 \%$ after the 5 th experiment, while their skills set the hypothesis as high as $60 \%$ 
after the 4th experiment (figure.8). This difference also shows that students are better able to establish hypotheses, but less able to provide an explanation of the test results. Explanations conveyed by students based on the results of the experiment are actually more in the direction of affirmation on the predictions given, not on the hypothesis.

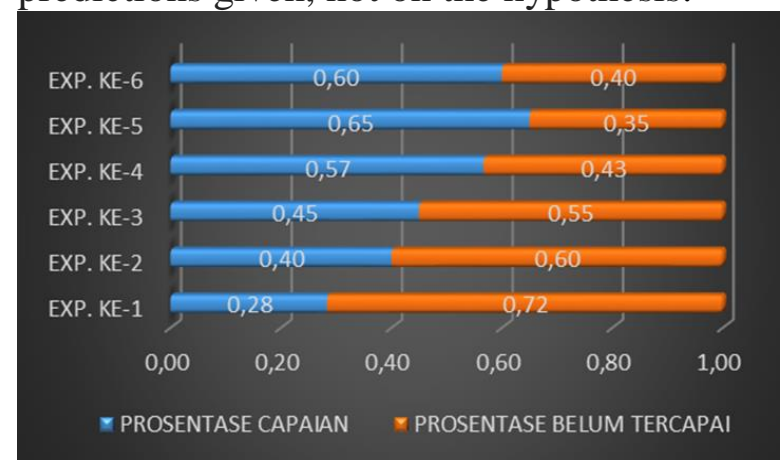

Figure 8. Graph of the average score percentage of scientific ability to ability to make a reasonable judgment about the hypothesis.

From the statements made by students and lecturers, they stated that handout developed for the Physics Experiment practicum was new to them. The handout that was developed can develop students' scientific skills and provide students with the experience of how they should work in a laboratory. In the Lab, they can simultaneously conduct and develop three experiments, namely observing, testing and applying, which have been separated.

\section{Discussion}

The main obstacle in the early stages of the implementation of a design lab learning model was writing lab reports. The low percentage of the average score of overall scientific abilities intended to be developed in this model was caused by the content of the lab report which was more comprehensive. The report should contain the process of experiment up to assessment and suggestion upon the experiment. The duration needed in this learning model was longer than a regular lab learning model. The outcome of the design lab learning model can be seen from the development of students' scientific abilities, the ability to design and conduct a testing experiment (Figure 1). The development of each sub scientific ability is also demonstrated in figure 2 up to 8 that the achievement of ability reaches above $60 \%$ after experiment 4 .

The ability of students to identify the hypothesis to be tested becomes the main gate to develop other abilities. The graph patterns in figure 2,3 , and 4 show that by recognizing the hypothesis to be tested, students move easily in designing experiments to be tested. This can be seen in the pattern of student skills development for this experimental model, where the increase in skills for all sub-skills shows the same trend. Its uniqueness is also the average percentage of scores that are almost the same. For example, the ability to set hypotheses in experiment 1 , the average percentage score for this sub-skill is only $25 \%$; apparently the achievements for other sub-skills are in this range.

By examining student lab reports, it appears that their ability to design experiments is largely determined by their ability to set hypotheses. The experimental design that was compiled should be in the form of steps to test the hypothesis. This can be seen from the lab reports in the initial experiments, the experimental design that they arrange is similar to the observation experiment pattern. The experimental steps compiled only lead to observations for gathering data. Next, they provide a description and conclusion of the data obtained. They do not test or prove because they do not set hypotheses or hypotheses are not clear.

Lack of ability to set hypotheses causes students to be difficult in designing experiments. Inappropriate design of the experiment will cause it not to be achieved from the experiments that have been specified in this test experimental model. The difficulty in establishing this hypothesis also impacts their ability to make predictions. Predictions that must be stated in the experimental testing model are arranged based on the hypothesis. A further consequence of this inability to establish this 
hypothesis is that the other skills that students are expected to master are undeveloped, because all the steps in this experimental model are based on their hypotheses. However, in the 4th or 5th experiment, the skills developed in this trial model have reached $60 \%$. Of all the skills developed from this test experimental model, the performance was stable and with almost the same value in the last two experiments (5th and $6^{\text {th }}$ ).

The relatively low ability of achievement in this model is the proficiency in deciding whether the prediction is arranged in accordance with the results and the ability to make statements that make sense from the hypothesis. From the initial experiments to the final experiment, the average percentage of scores achieved by students for these two sub-skills is lower than the other five skills. Students find it difficult to decide whether the predictions match the results because they have difficulty in making predictions from the experiments they do. At the end of the experiment for this model, they are required to make statements about the hypothesis based on the results of this experiment. How could they possibly make a statement about the hypothesis based on the results of an experiment if they had difficulty in establishing the hypothesis. This is the reason why the two skills above are relatively low compared to other skills in this model.

The time spent on completing the model testing experiment practicum is 40 to 50 minutes longer than classes that use the old guidelines. Similar research results also show this time difference, where design classes spend 40 minutes longer than non-design (ordinary) classes. ${ }^{14}$ The transfer of students' scientific skills in using physics concepts to solve biological problems also shows that the design class is on average 23.5 minutes longer than an ordinary class. ${ }^{15}$

\section{Conclusion}

The result sums up that lab design learning model can increase the scientific ability of students. The scientific ability developed in the study is the ability to design and conduct a testing experiments, consisting of seven sub-abilities. To know the improvement of these scientific abilities, students conducted six experiments followed by giving assessment based on their lab reports written after the experiment.

The report shows that the average score of nine sub-abilities has reached $62 \%$ after experiment 4 or after week 4 . However, there are two sub-abilities which have reached $60 \%$ after experiment 5 , which are the ability to decide whether the prediction and the outcome agree/disagree and to the ability to make a reasonable judgment about the hypothesis. The duration spent to complete the experiments in this lab design model is approximately 40 to 50 minutes longer than the regular class. The additional time is given because students must compile a more comprehensive report, including the report on the process of the experiment until giving assessment and suggestion for improvements, while usually in the lab, they used to make an interim report on the results of the experiment.

\section{Acknowledgement}

The abundance of thanks is directed to Research Team of Investigative Science Learning Environment (ISLE) Physics Network, whose result of the study is used as the main foothold of this study. Special thanks are also addressed to Ahmad Abtokhi, M.Pd., lecturer of Physics Experiment class, Nurun Nayiroh, M.Si, as Laboratory Assistant, and all Laboratory Assistants of Physics Experiment for the great cooperation built during the learning process.

\section{References}

1. Praranoto, Iwan. Diagnosis Science of Mathematics Science and Prescriptions for Improvement. 2012, http://www.scribd.com/doc/ 124873072/Handout-Binet-15-IwanPranoto

2. Pranoto, Iwan. 70 Per cent of Indonesian Children Difficult to Live in the 21st Century.

2012 , 
http://edukasi.kompas.com/read/2012/04/ 04/15495046/70.Persen.anak.Indonesia.S ulit.Hidup. di.Abad.21.

3. Ramadanti, Ruri. Peringkat Pendidikan Indonesia Masih Rendah. 2016, https://www. pikiranrakyat.com/pendidikan/pr-01258230/ peringkat-pendidikan-indonesia-masihrendah-372187.

4. Surya, Yohanes, Developing Mathematics and Natural Sciences Education with Simple Tools. 2012, http://astrophysicsblogs.blogspot.com/ 2012/12/mengembangkan-pendidikanmipa-dengan.html.

5. Karelina, A. and Eegenia Etkina. When and how do students engage in sensemaking in a physics lab?, Physics Education Research Conference, (Syracuse, NY, July 2006) edited by L. McCullough, L. Hsu, and P. Heron, AIP Conference Proc., 2007, Vol. 883, pp: 93 96.

PACS: 01.40,Fk; 01.40.gb; 01. 50.Qb.

6. Bybee, R. W. and Bruce Fuchs. Preparing the 21st-century workforce: A new reform in science and technology education, J. Res. Sci. Teach. 2006; 43(4): 349-352.

DOI 10.1002/tea.20147.

7. Etkina, E., A. Karelina dan M. RuibalVillasenor. How long does it take? A study of student acquisition of scientific abilities. Physical Review, Special Topics, Physics Education Research. 2008; 4, 020108: 020103-1-020103-15.

DOI: 10.1103/PhysRevSTPER.24.020108.

8. Etkina, E., D.T. Brookes, S. Murthy, A. Karelina, M.R. Villasenhor and A. Van Heuvelen. Developing and assessing student scientific abilities. Proceedings of the National STEM Assessment Conference, Oct. 19-21, Open Water Media, Inc., Washington, D.C. 2006:6880.

9. Etkina, E., S. Murthy and X. Zou. Using introductory labs to engage students in experimental design. American Journal of Physics. 2006;74: 979-982.

DOI: $10.1119 / 1.2238885$.
10. Etkina, E., A. Karelina, and M. RuibalVillasenor. Studying transfer of scientific reasoning abilities, In 2006 Physics Education Research Conference, (Syracuse, NY, July 2006) edited by L. McCullough, L. Hsu, and P. Heron, AIP Conference Proc. 2007;883: 81-84 PACS: 01.40,Fk; 01.40.gb; 01. 50.Qb.

11. Basid, A dan Andi Suhandi. Scientific Abilities Practice Analysis in Laboratory Learning: A Case Study in Physics Department of UIN Maulana Malik Ibrahim Malang. Proceedings of the 2015 Physics National Seminar, Palangkaraya. 2005:101-107.

12. Etkina, E., A. V. Heuvelen, D. Brookes, and D. Mills. Role of experiments in physics instruction - A process approach. The Physics Teacher. 2002; 40(6): 351-355.

PACS Numbers:01.40gb, 01.50Q,01. 90.

13. Etkina, E., A. Van Heuvelen, S. WhiteBrahmia, D.T. Brookes, M.Gentile, S. Murthy, D. Rosengrant, and A. Warren. Scientific abilities and their assessment, Phys. Rev. ST Phys. Educ. Res. 2006, 2. 020103: 1-15.

DOI: 10.1103/PhysRevSTPER.2. 020103

14. Karelina, A., Eugenia Etkina, Maria Ruibal Villasenor, David Rosengrant, Alan Van Heuvelen, and Cindy HmeloSilver. "Design And Non-design Labs: Does Transfer Occur?," In 2007 Physics Education Research Conference, (Greensboro, NC, August 2007) edited by L. Hsu, C. Henderson, and L. McCullough. 2007, AIP Conference Proceedings, 951: 92- 95.

15. Villasenhor, R.M., E, Etkina, A. Karelina, A. Van Heuvelen, A., Rosengrant, D., and Jordan, R. From physics to biology: Helping students attain all-terrain knowledge. In 2007 Physics Education Research Conference, (Greensboro, NC, August 2007) edited by L. Hsu, C. Henderson, and L. McCullough, AIP Conference Proceedings, 951: 96- 99.

PACS:01.4.-d, 01.40.Fk, 1.40.gb,01.50.qb. 